\title{
Assessment of the reliability of thermal protection of enclosing structures of buildings at the design and operation stages
}

\author{
Galina Shibaeva, Ekaterina Ibe ${ }^{*}$ and Denis Portnyagin \\ Khakass Technical Institute, Siberian Federal University, Department of Building, transport and \\ mechanical engineering, 655017, Abakan, Khakasia, Russia
}

\begin{abstract}
The article presents recommendations for assessing the heat and energy efficiency of a design solution for a building envelope based on the calculation of energy costs during typical periods of time. The recommendations are based on the analysis of defects in thermal protection of building envelopes during design and construction, by studying design documentation, thermal imaging, calculation and verification of building envelope components. Results of calculation of temperature in hazardous structural sites for the design winter conditions with the help of software that implements the finite element method are presented. In the present paper, the design solutions of the nodes of the walls of residential buildings are considered, where, during thermal imaging, thermal bridge are visible through the external walls. It is shown that the using of multilayer brick walls in the apartment houses in a sharply continental climate is irrational due to the rapid deterioration of the properties of the insulation layer. Also, the thermal protection of buildings is influenced by the design solution defects and violation of construction technology.
\end{abstract}

\section{Introduction}

The solution to the problem of increasing energy efficiency is inextricably linked with the problem of ecology. It is one of the priorities for the development of Russia. To solve the problem of improving the energy efficiency of the building and economy of utilities that consumes more than $30 \%$ of the fuel and energy resources of our country, the Federal Law No. 261 "On energy saving and energy efficiency" was adopted.

Scientists in many countries [1-8] are engaged in the problem of saving energy. At the same time, a correct and rational solution of this problem hasn't yet been found. Thermal protection of the external walls depends on many factors - the walls constructive solution, the type of insulation layer, the mode of operation and the region of building.

To ensure high energy efficiency of civil engineering, polystyrene foam, mineral wool and cellular insulation have found wide application. However, according to the results of studies, there are a number of conflicting opinions about their durability. Thus, studies of

\footnotetext{
*Corresponding author: katerina.ibe@ mail.ru
} 
the reliability of the thermal-moisture regime of external walls are relevant both in terms of thermal protection and durability of enclosing structures.

Nowadays multilayered wall structures are very popular in the residential buildings. Multilayered protecting designs are widely applied to decrease in heat losses of a building and satisfaction of requirements of normative documents last years in construction, including with accommodation inside of thickness of a wall of a layer of a thermal insulation.

Currently, in order to increase the energy efficiency of buildings and create a beautiful exterior of apartment buildings in Khakassia Republic, multi-layered exterior brick walls are used. However, multi-layered brick walls have disadvantages in terms of durability [917]. The insulation described above has a limited service life. At the same time, in real conditions, the heat-shielding properties of thermal insulations rapidly deteriorate. Since layers of different brick walls have different densities and thermal conductivities, they can deform in different ways.

The purpose of this study is to assess the reliability of the thermal insulating layer in multilayer brick walls for the conditions of Khakasia Republic.

\section{Methods}

A study of the thermal insulation of building envelops consists of three parts. The first part is a visual inspection with Thermal imaging FlirB200 to find cracks, structural defects, the heatlosses places and mold places.

The second part is a computation of structural sites using the soft package Elcut and SCAD Office to study the thermal field of the external wall and certain deformations of the facing layer of brick and comparison of results depending on the type of insulation.

The third part consists in the study of the properties of mineral wool insulation, depending on its humidity.

Mathematical modeling of the thermal regime of the structure in the cold season was carried out under the following boundary conditions:

- inside air temperature in the building $t_{i n t}=20^{\circ} \mathrm{C}$ (Russian standard GOST 304942011);

- outside air temperature $t_{e x t}=-37^{\circ} \mathrm{C}$ (Russian construction norm SP 50.13330.2012);

- heat transfer coefficient at the internal surface of the envelope $\alpha_{s i}=8.7 \mathrm{~W} /\left(\mathrm{m}^{2} \cdot \mathrm{K}\right)$

(Russian construction norm SP 50.13330.2012);

- heat transfer coefficient at the external surface of the envelope $\alpha_{s e}=23 \mathrm{~W} /\left(\mathrm{m}^{2} \cdot \mathrm{K}\right)$

(Russian construction norm SP 50.13330.2012)

\section{Results}

As objects for the study are use two apartment buildings in Abakan, built with the multilayered masonry (table 1). The houses were built in 2009.

The first object is a residential house on Torosova, 9 St. The building has a three-layer brick wall. Brick layer width $510 \mathrm{~mm}$ was taken as the carrier layer. Mineral wool plates width $150 \mathrm{~mm}$ are taken as insulation layer. Facing layer is made of red and yellow bricks.

The second object is a residential house on Bogdana Khmelnitsky, 159 St. The building has a three-layer wall. Aerated concrete, gas silicate autoclave D600 width $400 \mathrm{~mm}$ was taken as the carrier layer. Mineral wool plates width $100 \mathrm{~mm}$ are taken as insulation layer. Facing layer is made of decorative plaster. 
Table 1. Objects of research

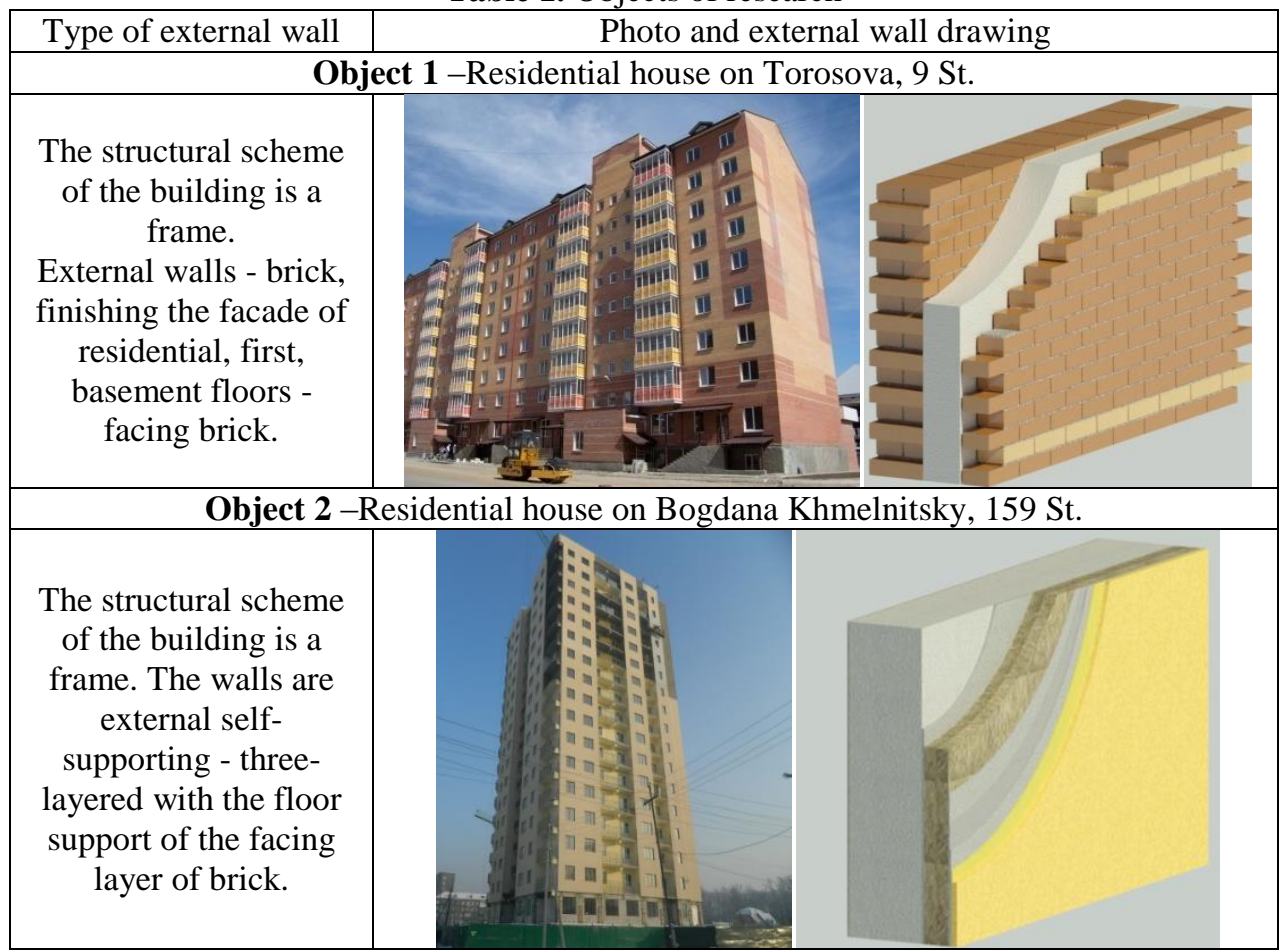

The results of the thermal imaging survey of object 1 show that the thermal circuit has significant defects after 9 years of exploitation. It is shown in Fig. 1 the thermal bridges are along the columns and floors, as well as intense heat loss from windows and balconies.
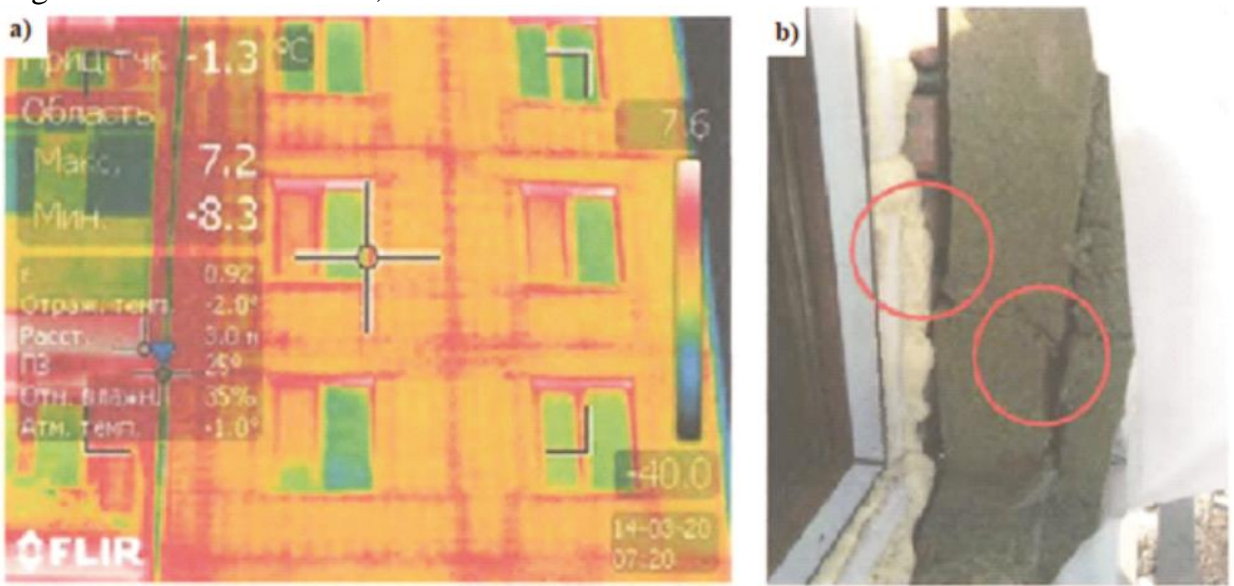

Fig. 1. The thermogram (a) and photo (b) of the part of the building's façade

From Fig. 1 the following disadvantages are visible:

- loose shrinkage between each mineral wood layer, due to the insufficient number of fixing dowels;

- loose shrinkage to the brickwork, due to the unevenness of the brick and protrusion of the mortar, leading to the inefficiency of the insulation; 
- Incorrect mineral wool plates layers. Plates must be laid in a staggered order so that the seam of the first layer of plates overlaps with the plate of the second layer.

The total thermal field of the façade (fig. 1, a) shows that the external wall has a large heat losses due to the violation of the properties of the insulation. After 9 years of exploitation the insulation layer has a humidity of 5-6\% in the winter season. Due to the low density of the mineral wool plate, the shrinkage of the thermal insulation layer was $1 \%$, which led to a violation of the integrity of the layer.

The design of the external wall of the objects is presented in the table 2.

Table 2. The external walls design solutions

\begin{tabular}{|c|c|c|}
\hline $\begin{array}{l}\text { Number } \\
\text { of object }\end{array}$ & $\begin{array}{c}\text { External wall (constructive } \\
\text { decision) }\end{array}$ & $\begin{array}{c}\text { Type of external wall for structural and } \\
\text { thermal insulation material }\end{array}$ \\
\hline 1 & 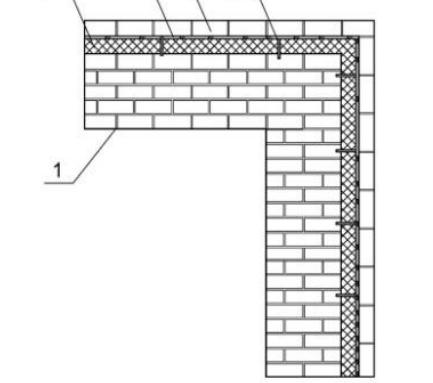 & $\begin{array}{l}\text { 1. Internal bearing layer width } 510 \mathrm{~mm} \\
\text { made of solid brick of plastic } \\
\text { pressing; } \\
\text { 2. Mineral wool } 45-75 \mathrm{~kg} / \mathrm{m}^{3} \text { with a } \\
\text { thickness of } 150 \mathrm{~mm} \text {; } \\
\text { 3. Air gap } 20 \mathrm{~mm} ; \\
\text { 4. Facing brick } 120 \mathrm{~mm} ; \\
\text { 5. Anchors. }\end{array}$ \\
\hline 2 & 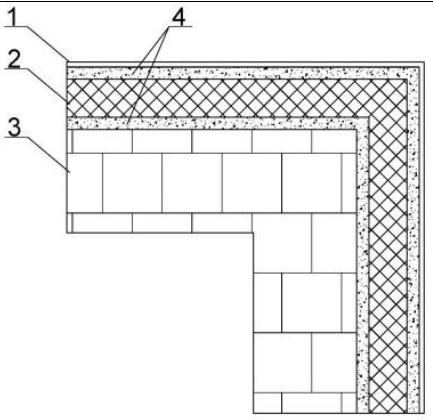 & $\begin{array}{l}\text { 1. Decorative plaster; } \\
\text { 2. Mineral wool } 45-75 \mathrm{~kg} / \mathrm{m}^{3} 100 \mathrm{~mm} \\
\text { thick; } \\
\text { 3. Internal support layer } 400 \mathrm{~mm} \text { thick } \\
\text { from aerated concrete, gas silicate } \\
\text { autoclave D600; } \\
\text { 4. The ceresit system, consisting of } \\
\text { ceresit } 190 \text { solution, front mesh, } \\
\text { second layer ceresit } 190, \text { CT } 15 \\
\text { primer. }\end{array}$ \\
\hline
\end{tabular}

The two solutions of the buildings thermal insulation of the external walls are presented. Calculations were done through the standard soft package Elcut, using an approximation of the Laplace equation by the finite element method. The existing version and the alternative version have been calculated. In both cases, polyurethane foam is considered as an alternative thermal insulation layer.

In addition, the heat-shielding properties of mineral wool insulation are considered depending on humidity. The deformations of the facing layer of masonry for conditions of Khakasia Republic in the winter period have been calculated.

\section{Discussions}

Thermal fields of objects under study are presented in Fig. 2, 3. It shown that the lowest heat flow in the wall construction with polyurethane foam is $11,9 \mathrm{~W}$, while in the wall construction with a mineral wool plate, the heat flow is $31,2 \mathrm{~W}$, more than 2 times. The reason is that polyurethane foam is applied to the surface without fasteners and has good intrinsic adhesion with other materials. In the other case, the heat flow is much greater due 
to the through-mounting of the screw through the insulation. Anchors for fixing mineral wool plates are thermal bridges, which leads to an increase in the humidity of the insulation layer in winter.
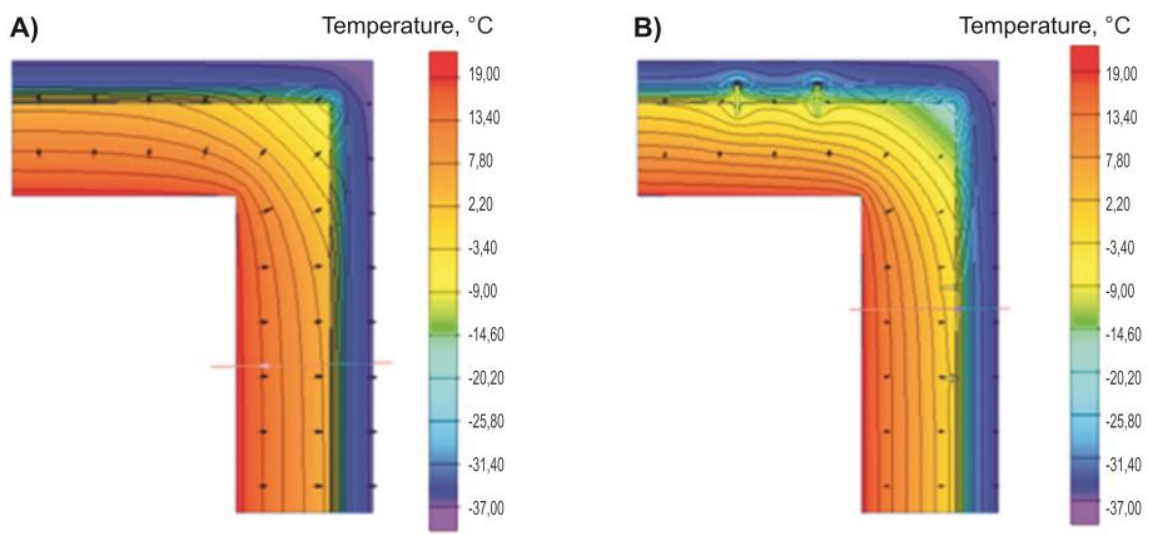

Fig. 2. The thermal field of external wall of the object 1: $a$ - real constructive solution; $b$-alternative constructive solution

Temperature, ${ }^{\circ} \mathrm{C}$

A)

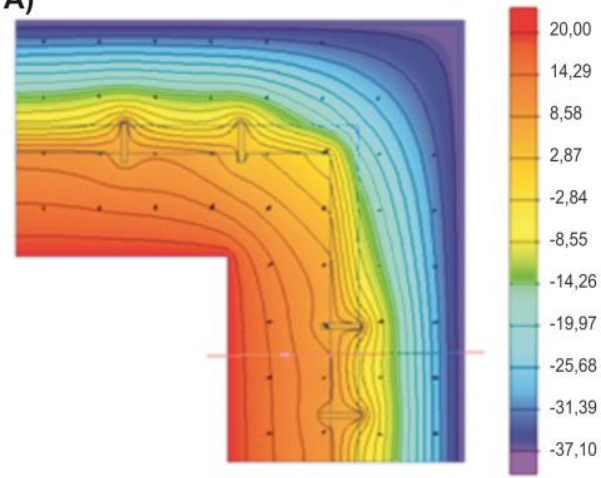

Temperature, ${ }^{\circ} \mathrm{C}$

B)

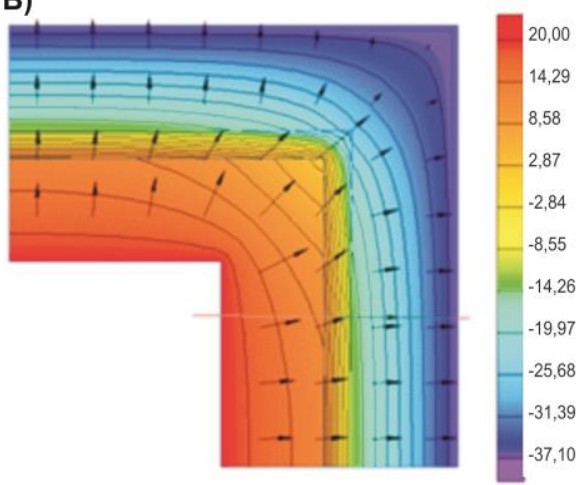

Fig. 3. The thermal field of external wall of the object 2: $a$ - real constructive solution; $b$ - alternative constructive solution

It should also be noted that the temperature difference in the case of using polyurethane foam is much less $\left(2{ }^{\circ} \mathrm{C}\right)$ than in the case of using mineral wool $\left(6^{\circ} \mathrm{C}\right)$.

According to calculations, the dew point in all cases is in the insulating layer. However, in the case of using polyurethane foam the dew point has less effect on the durability of exterior walls, since properties of polyurethane foam depending on humidity very slightly. Since the mineral wool is used in the objects 1 and 2, assessment of the insulation properties depending on humidity is a reasonable task.

The experiment was conducted to study the change in the structure of the mineral wool when it is wetted to a moisture content of 10\%. The results are shown in Fig. 4. 

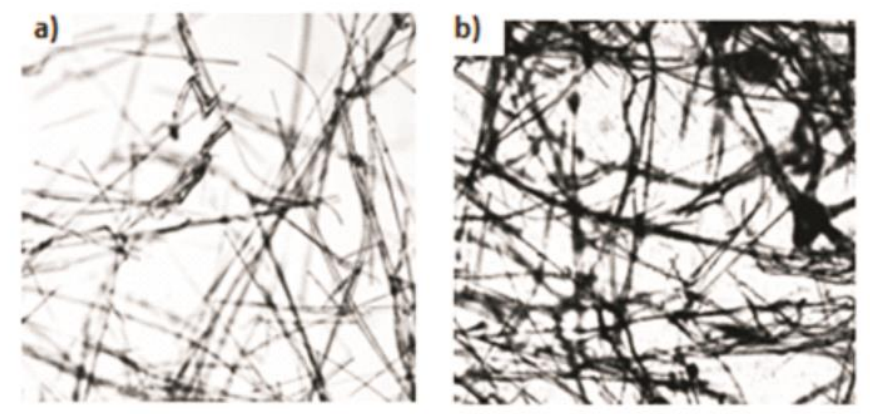

Fig. 4. Microstructure of mineral wool insulation: $a$ - before wetting; $b$ - after wetting

With an increase of the moisture content of the mineral wool insulation, the fibers change their location, become crumpled, and additional voids appear. Thermal conductivity coefficient of insulation increases by 10-22\% when moistened. Due to the fact that multilayer walls are difficult to repairing, increasing the moisture content of the mineral wool heater will significantly reduce the durability of external walls. Since Khakasia Republic has a large temperature difference between summer and winter, the thermal protection of buildings will quickly lose its properties.

Due to the fact that the facing masonry layer is attached to the load-bearing wall through flexible couplings pitch is $0,5 \mathrm{~m}$, significant temperature deformation of this layer is possible. The temperature deformations of the external wall corner in winter are shown in Fig. 5.

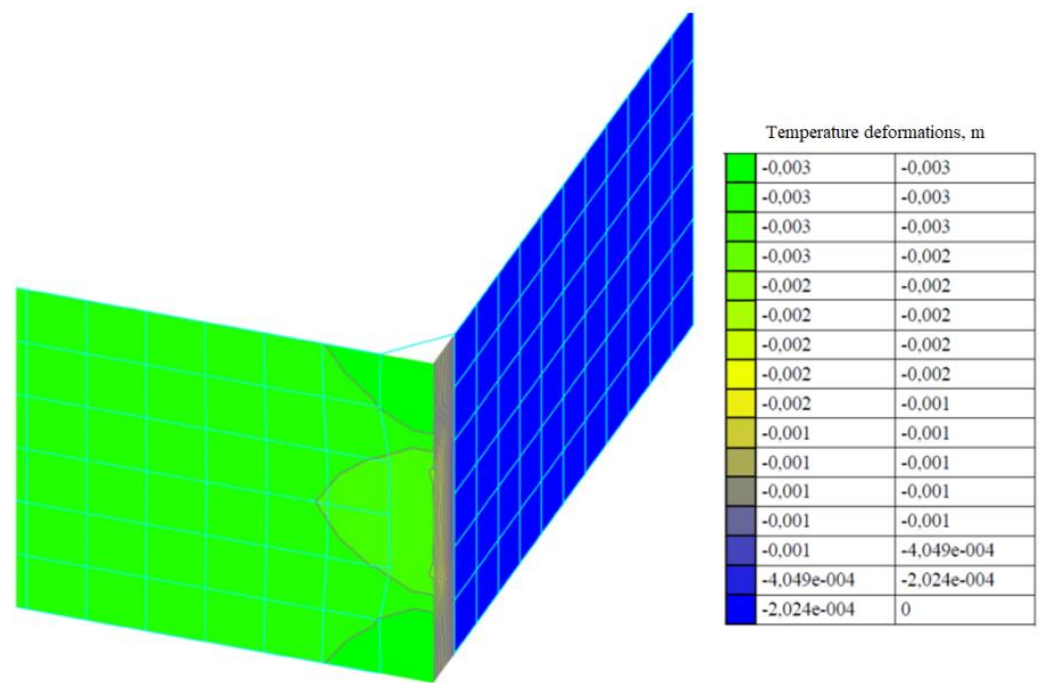

Fig. 5. Temperature deformation of external wall corner in winter, $m$

Temperature deformations are $1-4 \mathrm{~mm}$. With constant fluctuations in temperature, cracks formed in the masonry will expand, which will lead to the cracking of the entire facing layer vertically because the facing masonry layer frost resistance is 50 cycles. In this situation, the reliability of the facing layer depends on the reliable operation of flexible couplings pitch.

As a result of experimental studies, it was found that the service life stated in the TU does not correspond to the service life after carrying out field tests for specific climatic conditions, namely for Khakasia Republic. 
Visual inspections of buildings operated in the climate of Khakasia Republic have shown that many design solutions for external walls have now exhausted their thermal and operational reliability. And it is connected not only with objective reasons: difficult engineering-geological and climatic conditions, but also with subjective ones: lack of design experience, poor quality of construction, defects in factory-made structures and complete non-observance of the rules for operating buildings and structures.

Experience in the construction and exploitation of buildings in recent years has shown that the least studied was the question of the durability of an insulation layer material in a multi-layered external enclosure. The thermophysical properties of heat-insulating materials have not been studied enough; an effective insulation doesn't have an established standard service life for specific climatic conditions and specified operating modes. Durability is the most important indicator of any material, and it can be assessed by conducting short-term tests of materials with simulated operating conditions.

\section{Conclusions}

In this paper, a study was conducted of the heat-shielding properties of the external walls in the natural conditions of buildings, the analysis of their calculated and actual values of the reduced resistance to heat transfer; identifying the dynamics of changes in the heatshielding properties of multi-layer exterior walls with effective insulation in various operating conditions.

As a result of field studies, it was found that the service life of insulators declared in the TU is not lawful to apply for Khakasia Republic, as the standard values for each city are individual.

Studies have shown that multi-layered walls don't provide durability for the conditions of Khakasia Republic, since the climatic parameters of the region affect the humidity of the insulation and the cracking of the facing masonry layer. In connection with the low maintainability of this constructive solution, it is necessary to develop design solutions in more detail to ensure the conditions of facade ventilation and to prevent deformations.

\section{References}

1. J. Li, X. Meng, Y. Gao, W. Mao, T. Luo, L. Zhang, Case studies in thermal engineering. 11, 62-70 (2018).

2. Aidan Reilly, Oliver Kinnane, Applied Energy. 198, 108-121 (2017)

3. Glenn Reynders, Jan Diriken, Dirk Saelens, Applied Energy. 198, 192-202 (2017)

4. Rongling Li, Gamze Dane, Christian Finck, Wim Zeiler, Applied Energy. 203, 623-634 (2017)

5. Sami A. Al-Sanea, M.F. Zedan, A.M. Al-Mujahid, Z.A. Al-Suhaibani, Applied Thermal Engineering. 96, 92-106 (2016)

6. Stijn Verbekea, Amaryllis Audenaert, Renewable and Sustainable Energy Reviews. 82, 2300-2318 (2018)

7. O. Kaynakli, Renewable and Sustainable Energy Reviews, 16(1), 415-425 (2012)

8. W. Guo, X. Qiao, Y. Huang, M. Fang, X. Han, Energy and Buildings. 50, 196-203 (2012)

9. A. Trabelsi, R. Belarbi, K. Abahri, M. Qin, Building Simulation. 3, 107-115 (2012)

10. S.V. Kornienko, N.I. Vatin, M.R. Petrichenko, A.S. Gorshkov, Stroitel'stvo unikal'nyh zdanij i sooruzhenij. 6 (33), 19-33 (2015)

11. Yu.V. Halturin, Vestnik AltGTU im. I.I. Polzunova. 1-2, 78-81(2010) 
12. V.G. Gagarin, K.P. Zubarev, V.V. Kozlov, Vestnik TGASU. 1, 125-132 (2016)

13. A.I. Anan'ev, A.A. Anan'ev, Stroitel'naya teplofizika i ehnergosberezhenie. 3, 352-356 (2010)

14. N.P. Umnyakova, Vestnik MGSU. 1, 94-100 (2013)

15. V.G. Gagarin, G. Kuznecova, Tekhnologii stroitel'stva. 1(63), 6-22 (2009)

16. M.L. Bojić, D.L. Loveday, Energy and buildings. 26(2), 153-157 (1997)

17. L. Evangelisti, C. Guattari, P. Gori, F. Asdrubali, Building and Environment. 127, 7785 (2018) 